\title{
Exercise training improves free testosterone in lifelong sedentary aging men
}

\author{
Lawrence D Hayes ${ }^{1}$, Peter Herbert ${ }^{2}$, Nicholas F Sculthorpe ${ }^{3}$ and Fergal M Grace ${ }^{4}$ \\ 1 Active Ageing Research Group, Department of Medical and Sport Sciences, University of Cumbria, Lancaster, UK \\ ${ }^{2} S$ chool of Sport, Health and Outdoor Education, Trinity Saint David, University of Wales, Carmarthen, UK \\ ${ }^{3}$ Institute of Clinical Exercise and Health Science, University of the West of Scotland, Hamilton, UK \\ ${ }^{4}$ Faculty of Health, Federation University, Victoria, Australia
}

\begin{abstract}
As the impact of high-intensity interval training (HIIT) on systemic hormones in aging men is unstudied to date, we investigated whether total testosterone (TT), sex hormonebinding globulin (SHBG), free testosterone (free-T) and cortisol (all in serum) were altered following HIIT in a cohort of 22 lifelong sedentary ( $62 \pm 2$ years) older men. As HIIT requires preconditioning exercise in sedentary cohorts, participants were tested at three phases, each separated by six-week training; baseline (phase A), following conditioning exercise (phase B) and post-HIIT (phase C). Each measurement phase used identical methods. TT was significantly increased following HIIT $(\sim 17 \% ; P<0.001)$ with most increase occurring during preconditioning $(\sim 10 \% ; P=0.007)$. Free-T was unaffected by conditioning exercise $(P=0.102)$ but was significantly higher following HIIT compared to baseline $(\sim 4.5 \% ; P=0.023)$. Cortisol remained unchanged from $A$ to $C(P=0.138)$. The present data indicate a combination of preconditioning, and HIIT increases TT and SHBG in sedentary older males, with the HIIT stimulus accounting for a small but statistically significant increase in free-T. Further study is required to determine the biological importance of small improvements in free-T in aging men.
\end{abstract} Key Words

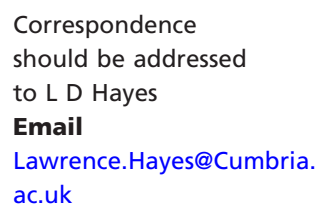

\section{Introduction}

Testosterone is a sex steroid hormone with profound influence on various tissues $(1,2,3)$. The precipitous decline in systemic testosterone with age is well described (4). Additionally, sex hormone-binding globulin (SHBG) is positively correlated with age, thereby attenuating the unbound fraction of testosterone, which is available for androgen receptor interactions $(4,5)$. With the ageassociated reduction in anabolic hormone production, reductions in cardiorespiratory fitness (6), muscle strength (7) and muscle power (8) are also observed. Furthermore, significant correlations between testosterone and measures of physical performance in older adults have been observed (9).
Whilst improvements in fitness can be achieved with exercise training in older adults $(10,11)$, the potential of aging men to increase systemic testosterone through exercise is poorly understood. Whilst some authors have reported elevated total testosterone (TT) in highly trained older males compared to controls (12), this is not always the case (13). For example, experimental data from our laboratory suggest masters athletes exhibit improved peak oxygen uptake, body composition and endothelial function compared with age-matched lifelong sedentary aging men, without any difference in TT $(14,15,16,17)$. Yet, we demonstrated that a six-week intervention of moderate aerobic exercise increased TT in said group of

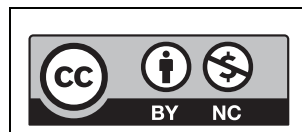


sedentary older males (11). However, SHBG was increased, which rendered bioavailable testosterone (bio-T) and free testosterone (free-T) unaltered compared to pre-training.

High-intensity interval training (HIIT) uses small volumes of exercise to bring about disproportionate increases in cardiometabolic health (18). Whilst we have reported lifelong exercise has no influence on basal TT, yet moderate aerobic exercise increases TT in sedentary older males, there is a paucity of data concerning the influence of short-term HIIT on TT and free-T in older males. Therefore, the purpose of the present investigation was to examine the influence of HIIT, following moderate aerobic conditioning, on androgen status in previously sedentary older males. We hypothesized a priori that testosterone would increase following HIIT.

\section{Materials and methods}

\section{Subjects}

Following familiarization with experimental procedures and approval to exercise by their general practitioner, participants were enrolled to the study, which was approved by the University of the West of Scotland Ethics Committee. Twenty-two sedentary, but otherwise healthy, males $(62 \pm 2$ years, with a stature of $175 \pm 6 \mathrm{~cm}$, and body mass of $91 \pm 16 \mathrm{~kg}$ ) participated. Subjects did not participate in any organized exercise program and had not done for $>30$ years prior to the period of moderate aerobic conditioning. To account for the contribution of conditioning exercise and HIIT, participants were tested at three phases; baseline (phase A), following conditioning exercise (phase B), and post-HIIT (phase C) using identical methods.

\section{Exercise training}

Participants undertook a six-week period of preconditioning, consisting of $150 \mathrm{~min} /$ week moderateintensity aerobic exercise, in line with the ACSM guidelines for exercise for older adults (19), followed by six weeks of supervised HIIT as previously described (14). Because aging men take longer to recover from a single HIIT session (20), sessions were performed every five days, for six weeks (nine sessions in total). Each session consisted of $6 \times 30 \mathrm{~s}$ sprints at $40 \%$ peak power output (PPO) interspersed with $3 \mathrm{~min}$ active recovery on a cycle ergometer (Wattbike Ltd., Nottingham, UK). Sessions were conducted in groups of between four and six participants
(๑) 2017 The authors

http://www.endocrineconnections.org DOI: 10.1530/EC-17-0082 and were the sole exercise performed during this time. To allow for comparison with other literature, training intensities were compared with power achieved at $\mathrm{VO}_{2 \text { peak }}$. Training intensity was $141+27 \%$ of power at $\mathrm{VO}_{2 \text { peak }}$.

\section{Body composition}

Stature was measured to the nearest $0.1 \mathrm{~cm}$ using a stadiometer (Seca, Birmingham, UK), and body mass and body composition were determined by a multi-frequency bioelectrical impedance analyzer (BIA (Tanita MC-180MA Body Composition Analyzer, Tanita UK Ltd.)). GMON software (v1.7.0, Tanita UK Ltd.) was used to determine absolute and relative body fat. Fat-free mass (FFM) was calculated by subtracting fat mass from total body mass.

\section{Blood draws and analysis}

Blood samples were collected 07:00-09:00 h, 48-72 h following the last exercise session as previously described (21). Serum concentrations of TT, SHBG and cortisol were measured by electrochemiluminescent immunoassay on the E601 module of the Roche Cobas 6000 (Burgess Hill, West Sussex, UK). Inter-assay coefficients of variation (CV) over a six-month period were $4.5,2.4$ and $4.2 \%$ for TT, SHBG and cortisol, respectively. Free-T was calculated using the Vermueulen equation (22).

\section{Data analysis}

Following confirmation of parametricity by a ShapiroWilk test of normality and Levene's test for homogeneity of variance, a one-way repeated measures analysis of variance (ANOVA) with post hoc Bonferroni correction was used to identify the differences between time points. Alpha level was set $a$ priori at $P<0.05$, and effect size (Cohen's $d$ ) was calculated. Data are presented as mean \pm standard deviation (s.D.).

\section{Results}

TT, free-T and cortisol pre- and post-HIIT are displayed in Fig. 1. TT increased from A to B $(13.2 \pm 5.5-14.6 \pm 6.1 \mathrm{nmol} / \mathrm{L}$, respectively $(P=0.007$, Cohen's $d=0.24)$ ) and remained elevated at $C$ compared to A $(15.4 \pm 6.6 \mathrm{nmol} / \mathrm{L}$ at phase C $(P<0.001$, Cohen's $d=0.36))$. SHBG increased following preconditioning $(P=0.016$, Cohen's $d=0.10(42.6 \pm 22.0$ and $45.0 \pm 23.9 \mathrm{nmol} / \mathrm{L}$ at $\mathrm{A}$ and $\mathrm{B}$, respectively)) and

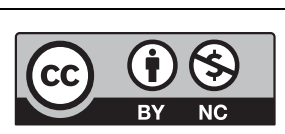

This work is licensed under a Creative Commons Attribution-NonCommercial 4.0 International License. 


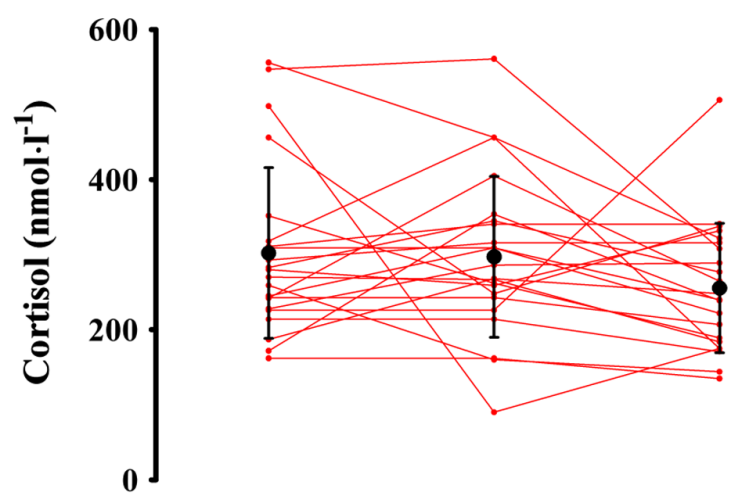

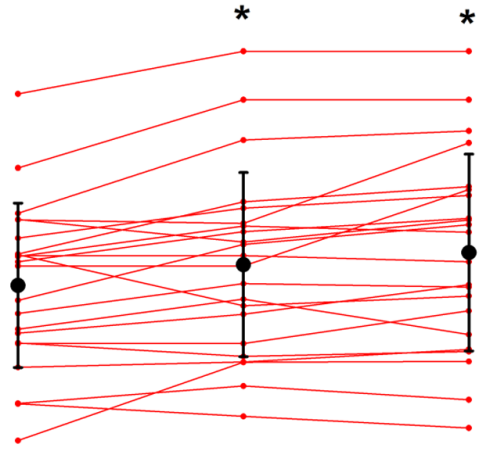

0
Cohen's $d=0.05))$ and from A to C $(256 \pm 86 \mathrm{nmol} / \mathrm{L}$ at phase C $(P=0.138$, Cohen's $d=0.46))$.

At phase A, body fat percentage was $24.4 \pm 11.6 \%$. Body fat percentage decreased $\sim 1.1 \%$ following preconditioning $(P=0.006$, Cohen's $d=0.10)$ and a further $\sim 2.2 \%$ following HIIT ( $P=0.008$, Cohen's $d=0.16)$, which meant body fat percentage was $\sim 3.3 \%$ lower at phase $\mathrm{C}$ than at A $(P<0.001$, Cohen's $d=0.28)$. FFM was $66.7 \pm 7.1 \mathrm{~kg}$ at baseline and was unchanged following preconditioning $(P=0.336$, Cohen's $d=0.06)$. This was followed by a $\sim 3.0 \%$ increase after HIIT $(P=0.005$, Cohen's $d=0.26)$, which was $\sim 3.6 \%$ greater than that at baseline $(P=0.001$, Cohen's $d=0.32)$.

\section{Discussion}

The main finding of this study is that preconditioning exercise and HIIT improves TT by $\sim 17 \%$ in previously sedentary older males, which was maintained after intervention despite the training volume reduction from $\sim 150 \mathrm{~min} /$ week to $\sim 3-6 \mathrm{~min} /$ week during the final training phase. In addition, progressive increases at each time point ensured free-T was elevated post-intervention, compared to pre-training. As such, HIIT may be a time-efficient nonpharmacological strategy in older males to maintain or increase endogenous testosterone concentrations.

We previously hypothesized that increased TT and SHBG were transient physiological responses to initiation of exercise training, and basal testosterone may return to baseline following prolonged training (11). However, the present study indicates HIIT confers a prolonged elevation in TT compared to pre-training ( 17\%).

Previously, we observed no increase in free-T following six-week moderate aerobic training in sedentary older males (11). However, the addition of HIIT stimulated a significant increase in the unbound hormone fraction, compared to moderate aerobic training. This occurred because of the $\sim 5 \%$ increase in TT, compared to the $\sim 2 \%$ increase in SHBG from phase A to C. As such, it is plausible that testosterone available for androgen receptor interaction was increased post HIIT, which may partly explain increased FFM.

Khoo and coworkers (23) indicated increased TT $(\sim 17 \%)$ following 24-week moderate-intensity aerobic exercise in middle-aged ( 44 years) obese men. Whilst the present study and study by Khoo and coworkers (23) both reported increased TT and SHBG, Lovell and coworkers (24) reported no change to TT, SHBG or free-T in an 
older cohort ( 74 years) following resistance or aerobic training. Importantly, participants were moderately active rather than sedentary as was the case in the present study and that of Khoo and coworkers (23). Taken together, the small body of comparable literature indicates that exercise training induces statistically significant, if not biologically or clinically relevant, increases in steroid hormones in sedentary middle to older aged men.

That previously sedentary aging males can increase TT following moderate exercise training, and free-T following HIIT, is an encouraging finding. Low testosterone is associated with diminished cognitive function, depression, osteoporosis and deterioration of muscle function (25). Therefore, the confirmation that exercise can increase serum testosterone is important for medical practitioners because exercise has been proposed as an initial treatment for low testosterone (26).

A limitation to the present investigation is that we utilized a single-arm observational design, rather than a randomized control trial. As such, it is difficult to conclude whether changes observed at phase $C$ were the result of HIIT or merely prolonged exercise intervention (of any modality). Moreover, as participants experienced beneficial alterations to body composition, it is feasible that the indirect effect of lower body fat may have resulted in increased free-T, rather than being purely the result of HIIT.

In conclusion, because preconditioning exercise increased both TT and SHBG, only a small increase in free-T was observed, which did not reach significance. However, the combination of preconditioning and HIIT appears a sufficient stimulus to improve free- $T$ in lifelong sedentary aging men. Further study is required to confirm these findings and establish the biological significance of small improvements in free- $T$ in aging men.

\section{Declaration of interest}

The authors declare that there is no conflict of interest that could be perceived as prejudicing the impartiality of the research reported.

\section{Funding}

This work did not receive any specific grant from any funding agency in the public, commercial, or not-for-profit sector.

\section{References}

1 Arazi H, Damirchi A \& Asadi A. Age-related hormonal adaptations, muscle circumference and strength development with 8 weeks' moderate intensity resistance training. Annales d'Endocrinologie 2013 74 30-35. (doi:10.1016/j.ando.2012.11.004)
2 Capllonch-Amer G, Llado I, Proenza AM, Garcia-Palmer FJ \& Gianotti M. Opposite effects of 17-beta estradiol and testosterone on mitochondrial biogenesis and adiponectin synthesis in white adipocytes. Journal of Molecular Endocrinology 201452 203-214. (doi:10.1530/JME-13-0201)

3 Dubois V, Laurent MR, Jardi F, Antonio L, Lemaire K, Goyvaerts L, Deldicque L, Carmeliet G, Decallonne B, Vanderschueren D, et al. Androgen deficiency exacerbates high fat diet-induced metabolic alterations in male mice. Endocrinology 2015157 648-665. (doi:10.1210/en.2015-1713)

4 Harman SM, Metter EJ, Tobin JD, Pearson J \& Blackman MR. Longitudinal effects of aging on serum total and free testosterone levels in healthy men. Journal of Clinical Endocrinology and Metabolism 200186 724-731. (doi:10.1210/jcem.86.2.7219)

5 Bjerner J, Biernat D, Fossa SD \& Bjoro T. Reference intervals for serum testosterone, SHBG, LH and FSH in males from the NORIP project. Scandinavian Journal of Clinical and Laboratory Investigation 200969 873-879.e1-11. (doi:10.3109/00365510903380886)

6 Grey TM, Spencer MD, Belfry GR, Kowalchuk JM, Paterson DH \& Murias JM. Effects of age and long-term endurance training on VO2 kinetics. Medicine and Science in Sports and Exercise 201547 289-298. (doi:10.1249/MSS.0000000000000398)

7 Martin JA, Ramsay J, Hughes C, Peters DM \& Edwards MG. Age and grip strength predict hand dexterity in adults. PLOS ONE 201510 e0117598. (doi:10.1371/journal.pone.0117598)

8 Metter EJ, Conwit R, Tobin J \& Fozard JL. Age-associated loss of power and strength in the upper extremities in women and men. Journals of Gerontology: Series A, Biological Sciences and Medical Sciences 199752 B267-B276. (doi:10.1093/gerona/52A.5.B267)

9 Aguirre LE, Jan IZ, Fowler K, Waters DL, Villareal DT \& ArmamentoVillareal R. Testosterone and adipokines ara are determinants of physical performance, strength, and aerobic fitness in frail, obese, older adults. International Journal of Endocrinology 20142014507395 (doi:10.1155/2014/507395)

10 Hayes LD, Grace FM, Sculthorpe N, Herbert P, Ratcliffe JW, Kilduff LP $\&$ Baker JS. The effects of a formal exercise training programme on salivary hormone concentrations and body composition in previously sedentary aging men. SpringerPlus 20132 18. (doi:10.1186/ 2193-1801-2-18)

11 Hayes LD, Sculthorpe N, Herbert P, Baker JS, Spagna R \& Grace FM. Six weeks of conditioning exercise increases total, but not free testosterone in lifelong sedentary aging men. Aging Male 201518 195-200. (doi:10.3109/13685538.2015.1046123)

12 Ari Z, Kutlu N, Uyanik BS, Taneli F \& Tavli T. Serum testosterone, growth hormone, and insulin-like growth factor-1 levels, mental reaction time, and maximal aerobic exercise in sedentary and long-term physically trained elderly males. International Journal of Neuroscience 2004114 623-637. (doi:10.1080/00207450490430499)

13 Hayes LD, Sculthorpe N, Herbert P, Baker JS, Hullin DA, Kilduff LP $\&$ Grace FM. Resting steroid hormone concentrations in lifetime exercisers and lifetime sedentary males. Aging Male 201518 22-26. (doi:10.3109/13685538.2014.977246)

14 Grace FM, Herbert P, Ratcliffe JW, New KJ, Baker JS \& Sculthorpe NF. Age related vascular endothelial function following lifelong sedentariness: positive impact of cardiovascular conditioning without further improvement following low frequency high intensity interval training. Physiological Reports 20153 e12234. (doi:10.14814/ phy2.12234)

15 Hayes LD, Grace FM, Sculthorpe N, Herbert P, Kilduff LP \& Baker JS. Does chronic exercise attenuate age-related physiological decline in males? Research in Sports Medicine 201321 343-354. (doi:10.1080/ 15438627.2013.825799)

16 Hayes LD, Sculthorpe N, Herbert P, Baker JS, Hullin DA, Kilduff LP \& Grace FM. Poor levels of agreement between serum and saliva testosterone measurement following exercise training in ageing men. Aging Male 201518 67-70. (doi:10.3109/13685538.2015.1018158) 
17 Knowles AM, Herbert P, Easton C, Sculthorpe N \& Grace FM. Impact of low-volume, high-intensity interval training on maximal aerobic capacity, health-related quality of life and motivation to exercise in ageing men. Age 201537 25. (doi:10.1007/s11357-015-9763-3)

18 Weston KS, Wisloff U \& Coombes JS. High-intensity interval training in patients with lifestyle-induced cardiometabolic disease: a systematic review and meta-analysis. British Journal of Sports Medicine 201448 1227-1234. (doi:10.1136/bjsports-2013-092576)

19 Riebe D, Franklin BA, Thompson PD, Garber CE, Whitfield GP, Magal M \& Pescatello LS Updating ACSM's recommendations for exercise participation health screening. Medicine and Science in Sports and Exercise 201547 2473-2479. (doi:10.1249/ MSS.0000000000000664)

20 Herbert P, Grace FM \& Sculthorpe NF. Exercising caution: prolonged recovery from a single session of high-intensity interval training in older men. Journal of the American Genriatrics Society 201563 817-818. (doi:10.1111/jgs.13365)

21 Hayes LD, Sculthorpe N, Herbert P, Baker JS, Hullin DA, Kilduff LP, Reed D, Spagna R \& Grace FM. Salivary testosterone measurement does not identify biochemical hypogonadism in aging men: a ROC analysis. Endocrine 201550 256-259. (doi:10.1007/s12020-014-0516-3)
22 Vermeulen A, Verdonck L \& Kaufman JM. A critical evaluation of simple methods for the estimation of free testosterone in serum. Journal of Clinical Endocrinology and Metabolism 199984 3666-3672. (doi:10.1210/jcem.84.10.6079)

23 Khoo J, Tian HH, Tan B, Chew K, Ng CS, Leong D, Teo RC \& Chen RY. Comparing effects of low- and high-volume moderateintensity exercise on sexual function and testosterone in obese men. Journal of Sexual Medicine 201310 1823-1832. (doi:10.1111/ jsm.12154)

24 Lovell DI, Cuneo R, Wallace J \& McLellan C. The hormonal response of older men to sub-maximum aerobic exercise: The effect of training and detraining. Steroids 201277 413-418. (doi:10.1016/j. steroids.2011.12.022)

25 Petak SM, Nankin HR, Spark RF, Swerdloff RS \& Rodriguez-Rigau LJA. American Association of Clinical Endocrinologists Medical Guidelines for clinical practice for the evaluation and treatment of hypogonadism in adult male patients - 2002 update. Endocrine Practice 20028 440-456.

26 Swerdloff R \& Anawalt BD. Clinical decisions. Testosteronereplacement therapy. New England Journal of Medicine 2014371 2032-2034. (doi:10.1056/NEJMclde1406595)

Received in final form 13 May 2017

Accepted 16 May 2017

Accepted Preprint published online 17 May 2017 http://www.endocrineconnections.org DOI: 10.1530/EC-17-0082
(C) 2017 The authors Published by Bioscientifica Ltd

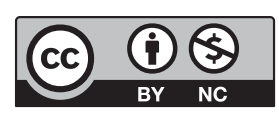

This work is licensed under a Creative Commons Attribution-NonCommercial 4.0 International License. 